\title{
Staffing a district psychotherapy service: further developments
}

\author{
C. R. Whyte
}

The adulf poychotheraplat model of stailing is conslderebly strengthened by a clinked directorate mencosment structure with a specilic locel poy scole for poychotheraplats. Whon such arrengements oxdst thoy cro uauclly welcomed by cliniclons and moncogrs. One recison for this ts that they make If poselble to ensure that senvices maintain good clinicel stendordis whille meeting the mancogetal oblecthres of the unll or truet. Undertying the auccess of these arrangements bs tho foct that by promoling sepcration and individuation thoy give senvices a fim lienttly. This is good for the service theelf and also for the unit or truet os a whole, becouses sepcration and individuction are the beats of co-operation and integration.

The difficulties of employing psychotherapists in the NHS have been outlined previously (Whyte, 1989). In that paper, which was written before the NHS reforms, I argued that an effective service must be able to base the appointment of staff on their expertise in psychotherapy: must have a fair career structure which rationally links pay and status with experience and responsibility; and must have a management structure which is able to ensure that work is conducted both competently and in accordance with the service's policies and priorities.

The paper compared the ability of two different staffing strategles (the multidisciplinary model and the adult psychotherapist model) to fulfl these requirements. It concluded that it was better to establish a team of adult psychotherapists drawn from the core professions, pay them by means of variation orders on the child psychotherapy scale and to make them clinically and managerlally accountable to a consultant psychotherapist.

Since that paper was written the NHS reforms have come into being and these have made further developments in the adult psychotherapist model possible. In particular, the model is strengthened when a service is organised as a clinical directorate with its own specific pay and conditions of service for psychotherapists.

\section{Clinical directorates}

A clinical directorate is a management entity in its own right. As such it is responsible for fulfilling the requirements of its own particular service specification; for managing its own pay and non-pay budgets; for appointing and managing its own staff; and for setting the clinical policies and standards of the service that it provides. It is also able, indeed expected, to ensure that the specialist nature of its work is understood and taken into account when the strategic direction of its unit or trust is being set and when business plans, contracts and quality standards are being negotiated.

The crucial point then about a clinical directorate is that it can align clinical and managerial objecttves. In being a formal part of the management structure it is accountable to its unit or trust and must work within its overall framework. But at the same time it can ensure that this framework is compatible with, and supportive of, its specialist clinical principles. The clinical director's role is cructal in this respect, as by being both the manager of the service and a senior clinician within it, the clinical director is able to ensure that the service is accountable and run in accordance with sound clinical practice.

\section{Pay and conditions of service}

A service must be capable of balancing the needs of its practitioners with those of the service as a whole. Indtwiduals need prospects so they can progress in their career with pay and status in accordance with their capabilities. At the same time their duties should be determined by the needs and priorities of the service, rather than simply by 
their ability. In other words they should be paid for what they do, but what they do should need to be done. A good pay scale helps to achieve this balance.

Psychotherapy has a special problem in this respect. There is no Whitley Council (or any other nationally agreed) pay scale for adult psychotherapists. Before the NHS reforms the preferred inroad into the problem was to appoint adult psychotherapists on the child psychotherapy scale by means of a personal varlation order granted by the Department of Health. This was, and still is, an unsatisfactory solution partly because the child psychotherapy grades do not equate with the needs of services for adults and partly because obtaining a variation order is a timeconsuming and elaborate process.

What is needed is a specific psychotherapy pay scale designed to meet the needs of services which provide psychotherapy for adults. Ideally, this should be a national Whitley Councll scale. Such a development is no doubt a long way off, and in the meantime the NHS reforms have made it possible for provider units to establish their own pay and conditions of service. This is possible for any staff group in the NHS trusts, but it is also possible in directly managed units for those groups of staff for whom there is no appropriate Whitley Councll scale.

In 1989 the Leicestershtre Dynamic Psychotherapy Service was formally established as a clinical directorate. It introduced specific local pay and conditions of service for dynamic psychotherapists in Aprll 1993. All its non-medical staff are now paid on this scale. The scale has four grades. The duties and responsibilities, and the level of previous experience and the qualifications necessary for each grade are clearly defined. The lower two grades are training grades. Progression or appointment to the two higher (non-training) grades requires the South Trent Training Certificate in Dynamic Psychotherapy or equitvalent advanced and specialist qualification. Built into the scale is a clear system of managerial and clinical accountability, grading reviews and regulations governing the composition of appointments committees. The scale thus does much to ensure that appropriate standards are maintained.
As far as I know, this is the first arrangement of its kind in the country. These arrangements are successful and welcomed by both cliniclans and managers. Why this should be calls for a deeper level of explanation.

\section{Individuation and separation}

The arrangements described in this paper do more than solve the problem of whom to employ and how much to pay. The reason why they are successful cuts deeper than this. Services, like individuals, have developmental needs. In particular they need to be firm and secure in their Identity in order to function effecttvely. In individual development this involves separation (1.e. achieving a sense of being a separate and autonomous person) and individuation (1.e. development of the individual person's particular and distinctive characteristics). These two processes, individuation and separation, work together to give rise to what Margaret Mahler calls "psychological birth" (Mahler et al, 1975). The development of a service involves similar processes, only in this case, separation is concerned with achieving the status of being "a service" within the overall organisation and individuation involves the development of that service's distinctive clinical function. The arrangements described in this paper are effecttve because they give the service an identity. They promote separation and individuation and give rise to the managerial birth of the service and the professional birth of its staff.

A clinical directorate is a managerial entity in its own right (separation) and able to organise Itself according to its distinctive clinical function (individuation). This is as crucial for psychotherapy as it is for any other service. Specialisation means adherence to certain key principles, some of which are bound to be different to those underpinning other services in the same unit trust. The effecttveness of a spectality rests on securing these differences. In other words, specialisation depends on individuation and separation. This, however, does not result in isolation as many seem to fear. On the contrary, It is services that lack a secure identity which tend to withdraw and become pervaded with persecutory anxiety. Separation and individuation are the basis of relatedness, they are the prerequisite for negotiation, cooperation and mutual understanding. The 
clinical directorate system of management thus provides the means by which the different specialities in a unit trust can begin to integrate and work together.

Psychotherapists, like most clinicians, work best when they feel sure of and secure in their professional identity. The problem for staff in the NHS is that psychotherapy is not recognised as a profession. It has not yet managed to separate and individuate out from the other health care professions, sufficiently to be one in its own right. The multidisciplinary model of stafing does nothing to address this problem. Instead, by maintaining the primacy of core professional identities, it explicitly seeks to prevent any such development. By contrast, the adult psychotherapist model, especially when it is backed by a specific psychotherapy pay scale, does much to enhance a psychotherapist's standing. To be employed as a psychotherapist, to be called one officially and to be paid as one, will help psychotherapists feel that this is what they are.

A pay scale not only helps to give birth to professional identity, but also encourages separation and individuation to occur within the profession. By defining the duties of and expertise needed for a number of distinct grades (eg. senior, principal) a pay scale establishes a rational hierarchy and defines how individuals may progress along it. This locates individuals in the profession, giving them a place to grow into and a place to grow from.

\section{Aclonowiedrement}

My thanks to Richard Jones for helping this paper separate and individuate out of the confusion of its earlier drafts.

\section{References}

MArIER, M., PINe, F. \& Birgman, A. (1975) The Psychological Bith of the Human Infant. Symblosts and Indtuiduation. Hutchinson and Co.

WHYTE, C. R. (1989) Stafing a district peychotherapy service. Psychiatric Bullettin, 1s, 596-598.

C. R. Whyte, Consultant Psychotherapist, Dynamic Psychotherapy Service, Humberstone Grange Clinic, Thurmaston Lane, Leicester LE5 OTA

\title{
Defeat Depression Campaign Fun Run
}

\author{
Sunday 9 April 1995 \\ 11 am, Battersea Park, London \\ Entry Fee $£ 3.00$ Distance 2 miles
}

Each entry fee will be matched by SmithKline Beecham and all proceeds will be put towards the funding of a

Defeat Depression Campaign educational package

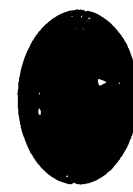

Defeat Depression

For an entry form and sponsor form please contact Christine Gear on 0712352351

A National Campaign organised by

The Royal College of Psychiatrists in association with The Royal College of General Practitioners 